\title{
Narrativa populista en el pensamiento político de Evo Morales y Nicolás Maduro
}

\author{
Populist narrative in the political thought \\ of Evo Morales and Nicolás Maduro \\ Michał Zbigniew DANKOWSKI ${ }^{1}$ \\ Kolegium Jagiellońskie - Toruńska Szkoła Wyższa \\ Marta JURGIELEWICZ² \\ Ateneum-Szkoła Wyższa w Gdańsku
}

\begin{abstract} leave no doubt that the narrative fits with populist ideas.

\section{Resumen}

1 https://orcid.org/0000-0003-1729-7595

Kolegium Jagiellońskie - Toruńska Szkoła Wyższa

m.dankowski@vp.pl

2 (C) https://orcid.org/0000-0003-0031-3544

Ateneum-Szkoła Wyższa w Gdańsku
\end{abstract}

The beginning of the 21st century brought an increase in the importance of populist politicians in some Latin American countries. The most important representatives of contemporary Latin American populism are Evo Morales from Bolivia and Nicolás Maduro from Venezuela. The narrative used in their speeches determines the political doctrine of both presidents. Various quotes from the examined discourses, then assigned to the presented linguistic characteristics,

Keywords: populism, Bolivia, Venezuela, indigenism, chavismo, political language

El comienzo del siglo XXI trajo consigo un aumento de la importancia de los políticos populistas en algunos países de América Latina. Los representantes más importantes del populismo contemporáneo latinoamericano son Evo Morales de Bolivia y Nicolás Maduro de Venezuela. 
La narrativa utilizada en sus discursos determina la doctrina política de ambos presidentes. Varias citas de los discursos examinados, luego asignados a las características lingüísticas presentadas, no dejan ninguna duda que la narrativa encaja con ideas populistas.

Palabras claves: populismo, Bolivia, Venezuela, indigenismo, chavismo, lenguaje político

\section{Introducción}

A principios del siglo XXI se puede observar un fenómeno en la escena política latinoamericana, que es el crecimiento de la popularidad de la izquierda con un fuerte acento populista. En varios países de la región se establecieron gobiernos con tendencias doctrinales similares. Los ejemplos más destacados son sin duda Hugo Chávez en Venezuela, reemplazado tras su fallecimiento en 2013 por Nicolás Maduro, quién está tratando de seguir la línea política de la Revolución Bolivariana iniciada por Chávez. Otro ejemplo brillante es Evo Morales, quién se incorporó a la presidencia boliviana en 2006, gobernando hasta 2019. En ambos casos los políticos recurrieron frecuentemente a la narrativa populista, para atraer la atención de las multitudes, que resultó ser una estrategia muy eficaz, gracias a la que pudieron ganar las elecciones y consagrarse presidentes de sus países. En este trabajo justamente se examina los recursos que utilizaron Maduro y Morales para impresionar a las sociedades de, respectivamente, Venezuela y Bolivia.

Obviamente Morales y Maduro no son los primeros presidentes populistas en América Latina. Esta doctrina con origen en la Antigua Roma, apareció en Latinoamérica junto con el gobierno del argentino Juan Domingo Perón en 1946. Años después Hugo Chávez, expresidente de Venezuela, se inspiró en la política de Perón. Tras ganar las elecciones presidenciales en 1999, promovió las ideas socialistas del bolivarianismo, basadas en la igualdad social, el nacionalismo, dirigiéndose a otros estados latinoamericanos (el llamado patriotismo hispanoamericano). Introdujo reformas con las que, la gente "olvidada" empezó a sentirse importante. Por lo tanto, se tomaron en cuenta los intereses de la sociedad indígena, se introdujo el acceso a la educación universal y al servicio sanitario. Más frecuentemente se celebraba referéndums para que todos los ciudadanos pudieran decidir sobre los asuntos más importantes para todo el país. Pronto Venezuela pudo salir de las deudas y el país se proclamó libre de analfabetismo (Dankowski et al., pp. 186-188). 
Se observa fácilmente la conexión no solo entre el estilo de gobernar de Perón y de Hugo Chávez y su sucesor Maduro, sino también de Morales en Bolivia. Este último también adoptó a su política las ideas de inclusión de la gente más débil y más pobre, la nacionalización de empresas, la mejora de las condiciones de vida de los más pobres, que han sido los objetivos comunes a todos los políticos populistas de América Latina.

En 2005 Morales como candidato en las elecciones subsiguientes se obligaba en su programa electoral a defender los derechos de la gente de origen indígena y el cese de la actitud hostil hacia la misma, luego llamada como la doctrina del indigenismo. Continuaba también con sus postulados de proteger el interés de los cocaleros y declamaba la necesidad de la estatalización de los hidrocarburos con finalidad de independizar Bolivia de las influencias internacionales, especialmente de los EE.UU. (Sivak, pp. 155-158).

Muy similares son las características más importantes del "chavismo" realizado por Maduro. Tal vez el gobierno venezolano apunta aún más a la ideología socialista, siempre en contra de la economía capitalista, como símbolo del eterno enemigo - los EE.UU, que luego llevó al país a una histórica crisis económíca y política al final de la década de 2010 (López Maya, pp. 159-185).

\section{Caracteristicas del populismo de Maduro y Morales}

La palabra populismo tiene origen en el latín - populus que significa la gente, el pueblo (Guardiola Rivera, p. 32). Una de las últimas definiciones científicas del populismo describe este concepto como: "una ideología que enfrenta la gente virtuosa y homogénea con un conjunto de élites y "los otros" peligrosos a quienes se les presenta como los que privan (o que tienen la intención de privar) a la gente soberana de sus derechos, valores, identidad y la voz." El populismo sigue ganando popularidad "por la falta de reacción de los partidos tradicionales a la serie de fenómenos como la globalización cultural y económico, [...] inmigración, caída de las ideologías, revelación de la corrupción de las elites. [...] La gente percibe a los políticos como complicados, distantes e inadaptados a la vida de la gente normal, incapaces, impotentes y egocéntricos." El populismo ofrece soluciones de común sentido presentadas en la forma comprensible para "el hombre de la calle" (Albertazzi et al., p. 3). Los estudios muestran que en el grupo de personas que es más susceptible o que está atraído por lo que ofrecen las populistas, se encuentran 
predominantemente los hombres, la generación mayor, los desempleados, gente que se dedica a trabajo manual y los campesinos (Albertazzi et al., p. 36).

De ahí se puede destacar cuatro rasgos del populismo muchas veces claramente mencionados por Morales y Maduro:

1. El pueblo forma una unidad y es moral. Morales y Maduro presentan con mucha frecuencia el conflicto entre lo "bueno" y lo "malo" mediante la yuxtaposición del pueblo y sus enemigos. "Yo le digo a nuestro pueblo siempre: allá ellos con su desesperación, su nerviosismo y su locura. Y acá nosotros, con nuestro amor, con nuestra paz, con nuestra visión de futuro, con nuestro espíritu redentor, libertario, revolucionario, socialista." (Maduro 2019a). La moralidad del pueblo denominan como humildad (Maduro 2019a):

[...] que nadie se envanezca hay que cultivar la humildad y yo humildemente como Presidente obrero le digo al pueblo, esta banda es tuya pueblo de Venezuela, este poder es tuyo pueblo de Venezuela, no es de la oligarquía, no es del imperialismo, es del pueblo soberano de Venezuela.

2. El pueblo es soberano. Es el derecho garantizado por las Constituciones de ambos países: "La soberanía reside en el pueblo boliviano." (Constitución de Bolivia, art. 7); “La soberanía reside intransferiblemente en el pueblo." (Constitución de Venezuela, art. 5). A este concepto apelan frecuentemente los populistas: "[...] ¿quién los eligió? ¿Maduro?, ¿la embajada gringa?, ¿quién eligió los gobernadores en este país? Los eligió el voto del pueblo [...]." (Maduro 2019a); "Venezuela tiene un pueblo que participa permanentemente en los procesos sociales, económicos y políticos." (Maduro 2019a); "Solo el pueblo pone, solo el pueblo quita." (Maduro 2019b)

3. La cultura y el estilo de vida es el valor supremo. Esta propiedad se manifiesta lo más claro en los enunciados de Morales en los que defiende los derechos de cocaleros y la gente indígena: " $Y$ mediante la Asamblea Constituyente pasamos del Estado Colonial "mendigo", que era Bolivia, a un Estado Plurinacional digno, ahora tenemos dignidad." (Morales 2014), en otro lado dice, que aparte de ser presidente, sigue siendo cocalero y quiere remontarse a sus raíces: "Yo vuelvo a las zonas del trópico Cochabamba para estar con mis compañeros”(Morales 2019b).

4. $\quad$ El líder es una parte del pueblo. Esos líderes suelen actuar en el nombre del pueblo, tienen habilidad de entender y descubrir los motivos infames de elites. Adicionalmente, llegan con una propuesta de solucionar 
los problemas: "Lo he exigido no para Evo, sino para el pueblo boliviano [...]. No es que nosotros queremos beneficiarnos sino quiero que el pueblo se beneficie." (Morales 2019b) y en otro lado (Morales 2014):

"En lo económico, yo tenía un mandato del pueblo boliviano que era nacionalizar nuestros recursos naturales, especialmente los de hidrocarburos: gas y petróleo. [...] No me quejo ni me alabo, sino muy contento porque eso se llama servir al pueblo boliviano."

La retórica de Morales es seguida por las palabres de Maduro (Maduro 2019a):

"Nosotros somos hombres y mujeres forjados en una lucha de carácter popular, yo vengo de las bases populares de los barrios de Caracas; vengo de una forja que solo se puede entender si se vive, solo se puede entender si has recorrido tú mismo los caminos de las luchas de los barrios, de los pobres, de los humildes."

" $Y$ quiero decirles que esta banda, esta llave y esta fuerza que llevo aquí no me pertenece a mí, esta banda y esta fuerza le pertenece al pueblo rebelde y soberano de Venezuela, es el pueblo el Presidente, es el pueblo dueño de estos símbolos."

Evo Morales habla sobre si mismo usando la tercera persona del singular, como si quisiera evaluar su gobierno desde cierta distancia y lo evalúa como ética.

¿A quién exactamente están apelando cuando mencionan el pueblo? Intentamos buscar la respuesta a esta pregunta en los textos de las Constituciones de Bolivia y de Venezuela. La primera sí contiene una definición. Según este acto el pueblo es el conjunto de los ciudadanos bolivianos, las naciones y pueblos indígenas, las comunidades interculturales y afrobolivianas (Constitución de Bolivia, art. 3). Desafortunadamente, la Constitución de Venezuela menciona el pueblo varias veces en todo el documento, pero no hay ninguna definición del pueblo, ni hablar de una tan detallada como la que está ubicada en la Constitución de Bolivia. Por lo tanto, el carácter del pueblo venezolano es ambiguo y su significado es un objeto de especulaciones entre la jurisprudencia.

Debido a su carácter plurinacional, el pueblo boliviano no consiste de una sociedad que comparte la misma sangre, las mismas tradiciones, ni la historia (los acontecimientos históricos son los mismos, pero existen descendientes de los conquistadores y de los indígenas) pero habita el mismo territorio (el territorio de Bolivia) y aunque existan las diferencias, la constitución garantiza a todos la igualdad de derechos a todos. 
El populismo presupone que el pueblo es totalmente decisivo, pero por otro lado hay populistas que sostienen que las elecciones son inútiles o tal vez no revelen la voluntad verdadera del pueblo. Sin embargo, hay que admitir que la mayoría de las experiencias de América Latina sugiere que los populistas no están dispuestos a destruir el marco democrático (Albertazzi et al., p. 17). No obstante, Nicolás Maduro tiene la fama de ser un dictador. De ahí resulta que además de ser denominados como populistas, ambos presidentes gobiernan sus países de diferente manera. Cabe entonces mencionar que no es posible amalgamar todos los populistas asumiendo que son iguales en cuanto a sus ideologías. Por lo tanto, si tratamos de ideologías, se prefiere sustituir el término con actitud o mentalidad para buscar los rasgos emergentes con mayor frecuencia (Albertazzi et al., p. 21).

\section{El lenguaje político}

Es una tarea bastante complicada tratar de definir y clasificar el concepto del lenguaje político. Según una de las definiciones más nuevas "el lenguaje político no es un lenguaje especial sino un uso especial de la lengua común [...] que no representa ningún rasgo distintivo en los otros niveles o dominios lingüísticos (morfológico y sintáctico) aparte de la existencia de un léxico propio." (Fernández Languilla, p. 13).

Es obvio que el lenguaje político está "dirigido a determinados sectores o grupos para el uso de los miembros que integran el grupo [...] y concierne de un modo más o menos directo a una amplia base social'. Así que está dirigido a los miembros del grupo amplio, generalmente a toda la sociedad, está también relacionado a los asuntos que incluyen varios sectores de la vida de esta sociedad. Por esta razón, el lenguaje político está influido por "términos procedentes [...] de jergas profesionales varias (economistas, arquitectos, etc.)" (Fernández Languilla, p. 16). De ello se deduce que el lenguaje político contiene tanto el vocabulario culto (científico) como el popular para abarcar todos los temas y para adaptar el mensaje a un grupo amplio. Por esta razón, como el discurso suele estar dirigido a los ciudadanos, los políticos no necesitan una formación específica - la intención es ser entendido para lograr objetivos anteriormente perseguidos (Núñez Cabezas, p. 17). La lengua que utilizan los populistas es aún más común (a veces ofensiva) porque el objetivo de los políticos es ser percibido como personas comunes. Se quieren parecer a miembros del pueblo, sin relación con el mundo turbio de la política (Albertazzi et al., p. 7). El lenguaje político tiene semejanzas con la lengua 
del periodismo - también considera este primero como lenguaje especial o sectorial y apunta que el lenguaje político cumple las siguientes características del lenguaje periodístico (Diezhandino Nieto, pp. 150-151):

- es el sujeto de la creatividad lingüística - tiene la capacidad de producir infinitas oraciones a partir de un conjunto finito de instrucciones sintácticas;

- su función no es criptica - sirve para ser entendido;

- contrariamente a la lengua científica o técnica, posee una relación significante, el significado es multívoco y depende del uso, connotaciones etc.

Este trabajo se concentra solamente en los discursos políticos externos que son diferentes de los de tipo interno en tanto que el primero está dirigido a un grupo amplio como ciudadanos, periodistas, durante encuentros oficiales que están trasmitidos por los medios. Este tipo de discurso contiene una combinación de la lengua del registro popular, pero también del lenguaje ambiguo, por ejemplo usando eufemismos.

De lo examinado hasta ahora resulta entonces que con el lenguaje político coexisten el vocabulario de origen técnico, las metáforas y las frases hechas. Las frases hechas y las metáforas son también partes de la lengua coloquial. La utilización de ellas convierte el estilo de enunciado en lo más popular, directo y como resultado más accesible a la gente, evitando ambigüedades o adornos. Es importante recordar que el lenguaje político incluye elementos de registros técnicos y coloquiales, pero no es ni uno, ni el otro de los mencionados en total. Es decir, no es un discurso jurídico o económico, ni es una charla entre amigos (Fernández Languilla, pp. 20-21). Sin embargo, para cortar la distancia entre un político y los oyentes, los primeros hablan como "hombres de la calle". Como ejemplo puede servir un fragmento de un discurso de Evo Morales que dice: "Antes del 2006, había cinco presidentes: 2001 Banzer; "Tuto" después 2002, después "Goni" en el 2003, Mesa 2004, 2005 Rodríguez." (Morales 2014). "Tuto" es un alias del ex-presidente boliviano Jorge Quiroga Ramírez y "Goni” es de Gonzalo Sánchez de Lozada. Claramente se puede observar la sustitución de los apellidos de los oficiales por sus sobrenombres. Los últimos tienen su origen en la lengua coloquial y no suelen aparecer en encuentros oficiales.

La función del discurso político no es informativa, sino agitativa. El mensaje enunciado debe estimular los destinatarios a una acción, según los propósitos del emisario (Fernández Languilla, pp. 20-21). Se identifica dos estrategias de influir al destinatario: la seducción que se refiere 
a los sentimientos del destinatario y la persuasión que apela al intelecto y la razón (Fernández Languilla, p. 49).

Teniendo en cuenta los recursos lingüísticos, el populista elije los persuasivos para describir su visión del mundo. Según Stanisław Barańczak un traductor y poeta polaco - hay ciertos elementos que se puede observar en la comunicación de tipo persuasivo (Barańczak, pp. 33-38):

- el mensaje es emocionante y provoca la reacción;

- se crea la comunidad mundial (en este caso la comunidad de los pueblos venezolano y boliviano) y del lenguaje;

- ocurre la simplificación del sistema de valores - es decir, la división del mundo entre "nosotros" y "ellos" simplifica el sistema de valor, presentado como el sistema de lo bueno y lo malo. Obviamente lo bueno está representado por "nosotros" (el líder y el pueblo) y lo "malo" por nuestros enemigos;

- aparece el mecanismo de recepción sin alternativas - el receptor no tiene que elegir nada porque el mensaje presenta una sola solución.

Lo arriba mencionado se integra muy bien al papel que tiene el líder populista. Él actúa como el pensador y el estratego, ya que propone soluciones previamente elaboradas.

En cuanto a las funciones agitativa y persuasiva, es digno de mencionar que ambos presidentes latinoamericanos, estableciéndose en la función del líder, utilizan deliberadamente héroes nacionales cuyas virtudes significativas están grabadas históricamente en la mente y la consciencia del pueblo, para que el oyente identifique los rasgos del héroe y los transmita a los presidentes. Esta técnica persuasiva invoca las autoridades cuyas virtudes son innegables para que la sociedad considere al líder igualmente honrado. Evo Morales habla de Túpac Katari: "Vamos a cumplir la sentencia de Túpac Katari: volveremos, volveremos y seremos millones." (Morales 2019b). En cambio Nicolás Maduro hace referencias a Simón Bolívar y otros libertadores: "Tengo los símbolos sobre mi cuerpo, la banda presidencial con el hermoso tricolor amarillo, azul y rojo, el hermoso tricolor del ejército del Libertador Simón Bolívar [...], el ejército del Libertador Simón Bolívar, no del Capitán América, el ejército de Bolívar, de Urdaneta, de Sucre, de Páez." (Maduro 2019a), pero también habla de Hugo Chávez. Hay que mencionar que Simón Bolívar es también el héroe nacional de Bolivia y los nombres de dos países llevan su apellido: Estado Plurinacional de Bolivia y República Bolivariana de Venezuela.

Para entender el sentido del discurso político es imprescindible conocer

el contexto. Como contexto consideramos todas las circunstancias extra 
lingüísticas en las que incluimos aspectos sociales, históricos y psicológicos. Observamos que hacer el análisis sin investigar el marco que abarcaría los factores previamente mencionados, impediría la comprensión completa del mensaje del emisor. Sin embargo, no es ninguna singularidad del discurso político, ya que nuestra observación concierne todos los tipos de mensajes. Los apartadores anteriores contienen la información general sobre los presidentes y sobre la situación actual en sus países para facilitar el entendimiento de los fragmentos de los enunciados abajo presentados.

\section{Las peculiaridades populistas en los discursos de Morales y Maduro}

Como se ha apuntado previamente, definir inequívocamente el lenguaje político no es una tarea fácil. Sin embargo, se puede destacar sus atributos más característicos. Como ejemplo pueden servir los discursos de Evo Morales y Nicolás Maduro, que poseen fuertes influencias populistas en su narrativa. Las características más importantes del lenguaje político de los populistas latinoamericanos se pueden clasificar de la siguiente manera:

\subsection{Destinatario}

El destinatario es la figura obligatoria para el desarrollo de la narrativa política en el régimen democrático. Se define dos tipos de destinarios (Fernández Languilla, p. 31):

- directo - el que está denominado, al que apela el emisor y que es un individuo concreto, por ejemplo "Señor Presidente", "estimados diputados" etc.

- indirecto - que es un conjunto de personas a las que el mensaje está dirigido. Sin embargo, la presencia del destinatario de este tipo no es tan perceptible como en el caso del destinatario directo debido al carácter grupal del destinatario indirecto. Realmente es el destinatario indirecto, quien tiene el rol más significativo, porque posee la capacidad y el poder de tomar decisiones necesarias para alcanzar el objetivo del emisor, porque justamente de este depende el éxito de un político. Entonces el discurso al destinatario indirecto tiene función agitativa. Por lo tanto, para que el emisor cumpla sus objetivos es necesario ejecutar una buena estrategia persuasiva. Y así lo hace por ejemplo Maduro, cuando dice: "Venezuela bella tiene que brillar compadres." (Maduro 2020) o también de esta manera: "Con todo respeto, es con ustedes magistrados 
y magistradas, es con ustedes constituyentes, es con ustedes poderes públicos, es contigo Fiscalía, es contigo Contraloría, es contigo Defensoría del Pueblo, es con todos. Es contigo, periodista, comunicador, es contigo también." (Maduro 2019a). Aunque parezca que el presidente venezolano se refiera al destinatario directo por el uso de singular, no lo es. Es la sinécdoque con la que designa una parte del grupo (un periodista del grupo de todos los que se dedican al periodismo) con la intención de hablar sobre todo el grupo. Por otro lado, el rasgo muy distintivo para Evo Morales, tal como para muchos otros populistas latinoamericanos, es dirigirse utilizando la frase "hermanas y hermanos", también durante los mítines oficiales.

\subsection{Llamadas al receptor}

Este tema corresponde con el apropiado uso de los pronombres personales. El sujeto puede aparecer en la primera persona singular (cuando el político cuando usa yo) o plural (nosotros). Los dos se sustituye también con la forma impersonal "se dice" etc. La llamada, no sirve para identificar el sujeto, sino para invocar a la audiencia y frecuentemente está utilizada para expresar la cortesía y diplomacia. De los tres tipos existentes de la llamada al receptor, es el imperativo más característico para el populismo, ya que el uso del pronombre personal (usted) o el nombre propio es común en cada discurso (Fernández Linguilla, p. 74). Lo que distingue a la narrativa populista es el frecuente uso de los imperativos, que suelen ser demandas políticas, tal como en el caso de cuando Maduro estaba dando advertencias a la Unión Europea para que no se meta en los problemas internos de Venezuela, con las siguientes palabras: “iQuieto, detente Europa!, ¡Unión Europea, detente!' (Maduro 2019a).

\subsection{Sintaxis}

No existe una formula especial que utilizan los políticos en cuanto a las construcciones sintácticas. Sin embargo se puede nombrar algunas modalidades más frecuentemente usadas por los populistas. Entre otras se distingue:

\subsubsection{El uso de pronombres personales}

Se distingue dos clases de discursos: individuales y colectivos. En la primera clase el pronombre personal utilizado, es el de primera persona del singular yo. En la segunda clase, se utiliza la primera persona del plural. Aparte de las diferencias gramaticales obvias, como la conjugación de los verbos 
y la concordancia de los adjetivos con el singular o plural, hay que notar que el uso de plural se comprende como evadir la responsabilidad individual (Fernández Lagunilla, I, p. 53). Además, la referencia al yo en los discursos políticos es cada vez menos frecuente, pero se inscribe en la corriente populista, ya que "el emisor aparece [...] bajo la forma de la primera persona, es decir el yo, pero al servicio de los ciudadanos, a los que se les puede interpelar directamente, en una relación de intercambio verbal y no verbal' (Fernández Lagunilla, I, p. 42). Sin embargo, cuando el político usa la primera persona de plural nosotros subraya su afiliación al grupo al que invoca. Además, el contenido de su enunciado no es del interés suyo, sino del todo grupo, es el interés público. En esta forma suele hablar Maduro: "Yo no lo hago para arrancar aplausos, lo hago porque estoy obstinado de la indolencia." (Maduro 2019a).

También cabe mencionar los casos de utilización del sujeto gramatical en tercera persona (p.ej. el gobierno ha decidido que...) o de las construcciones lingüísticas que permiten evitar la referencia personal y la utilización de los pronombres personales. Por lo tanto, se los sustituye con las estructuras como "hay que", "se dice que", "es obvio que" (Fernández Lagunilla, I, p. 43). Frecuentemente este tipo de construcción es usada por Morales, por ejemplo en su discurso tras haber recibido el Doctorado Honoris Causa de la Universidad de Entre Ríos en Argentina: "Toda la historia... se sabe muy bien [...]." (Morales 2014).

La utilización del plural corresponde a menudo a la parte del discurso en la cual se busca las virtudes en el partido propio, mientras tanto criticando a los adversarios. La presencia de la forma impersonal produce una impresión de un principio sobradamente conocido. Los enunciados analizados pertenecen predominantemente a la clase de los discursos colectivos, ya que a ambos presidentes se consideran populistas y forman parte de un grupo mayor.

\subsubsection{El uso de figuras retóricas}

Entre las figuras retóricas que aparecen frecuentemente en el lenguaje político se destacan las metáforas y los eufemismos cuyas características comunes son que el significado literal no tiene nada que ver con el mensaje que el emisor está enviando. También las repeticiones y las estructuras utilizadas con finalidad de ordenar la enunciación son unas formas populares en el lenguaje populista. 


\subsubsection{Metáfora política}

Las metáforas ayudan a reforzar el mensaje. Son figuras retóricas dónde se juntan las palabras que tienen un significado diferente con la finalidad de crear un sentido nuevo, más poético, diferente del sentido físico. Los elementos integrantes comparten alguna semejanza de significado que permite sustituir uno por otro en la misma estructura.

Las metáforas suelen ser una estrategia indirecta gracias a la que los políticos pueden hablar sobre temas delicados. Pero una de características que debería poseer un buen discurso político es la implementación de los medios estilísticos. La finalidad del empleo de ellos "es hacer que la compresión de cuanto se exprese penetre con viveza en la percepción, y conmueva la sensibilidad." (Ortega Carmona, p. 107). La utilización de las metáforas puede parecer levemente culta por un lado, pero simultáneamente aproxima el discurso al "hombre de la calle" y facilita la comprensión rápida del argumento, porque „el enmarcado tiene que ver con elegir el lenguaje que encaja en tu visión del mundo. Pero no solo tiene que ver con el lenguaje. Lo primero son las ideas. Y el lenguaje trasmite esas, evoca esas ideas." (Larkoff, p. 7). Por lo tanto, los políticos usan metáforas para facilitar o explicar las nociones políticas o abstractas porque las metáforas forman los constructos lingüísticos "de los que se desprende una gran carga afectiva como consecuencia de las asociaciones subjetivas que establecen." (Fernández Lagunilla, I, p. 46). La carga afectiva puede ser positiva o negativa. La negativa es utilizada en discursos contra el adversario, mientras que la positiva se usa para subrayar el contenido, pero también para animar a los oyentes. Entre las metáforas más frecuentes en los discursos de Morales y Maduro se observa las del ámbito:

- religioso / moral: "El 2020 tiene que ser el año en que Venezuela se ponga de pie, se recupere y brille con el brillo de Dios." (Maduro 2020).

- bélico: "Y otra vez, compitiendo directamente, cara a cara con los opositores. [...] a Venezuela le ha tocado estar en la primera línea de la batalla." (Maduro 2019a); "Quiero decirles: vamos a continuar [...] luchando para que no se cayera Bolivia."(Morales 2019b); "Repito nuevamente: a quien no termina la vida, la lucha sigue." (Morales 2019b); "[...] la tecnología puesta al servicio de la muerte y el comercio de armas sin escrúpulos, se han incrementado."(Morales 2019a); "quiero decirles nunca podremos dudar de nuestras luchas. Nunca podremos vacilar de su lucha por la liberación de los pueblos." (Morales 2014); "Somos una fuerza popular que ha dado una batalla 
inmensa de américa Latina por abrir un camino pacífico electoral legal constitucional para los cambios profundos para los cambios progresistas, para los cambios revolucionarios." (Maduro 2019b). Este último fragmento proviene de un discurso de Nicolás Maduro en el que se refiere mucho a las palabras connotadas con el acto de combate y las entrelaza con las relacionadas con la paz. Es un curioso truco del presidente venezolano, porque Maduro incita a la lucha y apela a la paz simultáneamente, por lo cual la intención del emisor es ambigua, si no imposible de realizar.

- personificación: un ejemplo ideal es la ecología. Los desastres medioambientales advierten a la humanidad y la tierra no es solo un lugar en que residen todas las especies, sino también posee el papel de la madre (Morales 2019a):

Nuestra casa, la madre tierra, es nuestro único hogar y es reemplazable. Cada vez sufre más incendios, más inundaciones, huracanes, terremotos, sequías y otras catástrofes. [...] Cada día sufrimos la desaparición de especies, la erosión de la tierra, la desertificación y la deforestación. [...] Hermanas y hermanos estamos advertidos de que si seguimos este curso de acción para el año 2100 llegaremos a un incremento de los 3 grados centígrados.

- del sufrimiento y los sentimientos heridos: "Por ello, la Organización de las Naciones Unidas debe vigilar y exigir el cumplimiento integral de las decisiones de la Corte para que ambos pueblos sigamos negociando de buena fe para cerrar las heridas abiertas." (Morales 2019a)

- relacionadas con fenómenos meteorológicos: "Hoy iniciamos un nuevo ciclo, yo lo dije: llueva, truene o relampaguee, Venezuela va a seguir por el camino de la democracia y la paz." (Maduro 2019a).

- de actuar y animar a la acción: "[...] tenemos el poder en las manos y las máximas responsabilidades." (Maduro 2019a); "[...] pueblo noble de Venezuela que es capaz de dar la vida en las calles." (Maduro 2019a); "Bolivia ha tomado el camino para derrotar a la pobreza y al subdesarrollo." (Morales 2019a); "Que somos mayoría, que somos alegría, que somos el pueblo de Hugo Chávez Frías.” (Maduro 2019b).

- símbolos nacionales: "Este tricolor [...] es el mismo tricolor [...] porque fuimos fundados y libertados por el mismo ejército, un solo ejército, el ejército de los libertadores y de las libertadoras, por Bolívar, por Manuela Sáenz." (Maduro 2019a). Tricolor es la metáfora 
de bandera de Venezuela que tiene los mismos colores que la de Colombia y de Ecuador.

- culinarias: la metáfora de la modificación de las proporciones de 82\% y $12 \%$ de ingresos después de la nacionalización de los hidrocarburos en favor de Bolivia: "Yo decía "hay que voltear la tortilla" como decimos." (Morales 2014).

Las metáforas que suelen repetirse en los discursos populistas lo más frecuentemente, son las que se refieren a la "batalla" y a la "rebeldía". Cabe mencionar que cuando los presidentes animan a la lucha, es con el fin de mejorar las condiciones de la vida y de defender el honor nacional. Las acciones del adversario de carácter semejante serán denominadas como "guerra" y su objetivo será "el servicio al muerto". Esto lleva a una conclusión que la inclusión de las metáforas bélicas en los discursos se integra en la imagen de un político populista que sugiere la división del mundo entre los buenos y los malos.

\subsubsection{El eufemismo político}

Los eufemismos aparecen en la comunicación de la lengua política para evadir los temas difíciles y evitar decir algo claramente y directo (Fernández Lagunilla, I, p. 48). Esta figura retórica es usada frecuentemente tanto por Morales, como por Maduro. Abajo se indica algunos ejemplos de sus discursos.

Es evidente que Evo Morales nunca estuvo a favor de los EE.UU., pero no lo pudo decir directamente, para no sufrir sanciones del país más poderoso de América. Entonces utilizó eufemismos para explicar su doctrina política, como por ejemplo en estos casos: "Observamos con preocupación el deterioro del sistema multilateral, producto de las medidas de carácter unilateral impulsadas por algunos estados que han decidido desconocer los compromisos, la buena fe en las estructuras globales construidas para una convivencia sana [...]." (Morales 2019a). Otra manera de decir que no se está de acuerdo con la política estadounidense fue esta frase: "Bueno nos damos cuenta que están en muchas diferencias." (Morales 2019b).

En otro caso el eufemismo ha sido utilizado por Morales para sustituir el verbo morir y reemplazarlo por una forma más suave: "Cada día sufrimos la desaparición de especies, la erosión de la tierra, la desertificación y la deforestación." (Morales 2019a). También Maduro no para de usar eufemismos, como sucedió cuando se refería al acto de autoproclamación de Guaidó para el cargo de presidente de Venezuela. Maduro dijo entonces: " $Y$ hoy se comieron la luz, se comieron la luz por eso anuncio." (Maduro 
2019b), que obviamente no tenía nada que ver literalmente con la luz, ni tampoco con una comida.

Los eufemismos también sirven para excluir las connotaciones desagradables de una palabra y sustituirla con una que podría evocar asociaciones positivas.

Entre las técnicas que se aplican para conseguir el objetivo a causa de un eufemismo se destaca la redundancia, que es hablar con muchas palabras que contienen poca información (Hernando, pp. 179-180). Este tipo de manipulación es común para los discursos populistas. Un ejemplo de lo que decía Maduro (Maduro 2019a):

" $Y$ si preguntan por cada uno de nosotros, y si ustedes preguntaran quién es Maduro, y yo mismo me preguntara quién soy yo. A veces lo hago ante tanto ataque, ataques brutales de una derecha extremista, fascista, compañeros, sí fascista, no podemos ahorrar los calificativos, en el caso de una derecha como la venezolana que ya ha infectado de su fascismo, su intolerancia y su extremismo a la derecha latinoamericana y caribeña como se ha infectado, veamos el caso de Brasil y el surgimiento de un fascista como el presidente Jair Bolsonaro."

El fragmento presentado sí que contiene muchas palabras: el locutor caóticamente se entera de los fascistas, de las derechas latinoamericanas, hasta del presidente de Brasil. La única cosa que falta es la respuesta a la pregunta formulada al principio: ¿Quién es Maduro?

\subsubsection{Repeticiones}

\subsubsection{Anáfora}

La anáfora es una figura retórica que consiste en la repetición de una o varias (depende del tipo de prosa o normas en la poesía) palabras al principio de un verso o enunciado. Su función es enfatizar el significado al repetir el parte más importante. El lenguaje de los populistas contiene unos ejemplos del uso de la anáfora: "Venezuela es una democracia no solo sólida en lo electoral, Venezuela es una democracia de nuevo tipo, es una democracia en construcción para una visión de democracia socialista, comunal; una democracia revolucionaria, una democracia radical, de raíz." (Maduro 2019a) o “'Eso es insulto! ¡Eso es inmoral y eso es inadmisible!' (Morales 2019a).

\subsubsection{Sinonimia}

En el lenguaje político se observa el empleo de los sinónimos. De forma general, estas figuras retóricas son muy útiles en las situaciones que exigen la sustitución 
de una palabra por otra. El uso del mismo vocabulario en el mismo texto o enunciación suena mal y por lo tanto se suele implementar los sinónimos. Sin embargo, los políticos buscan las equivalentes también para enfatizar su mensaje. Esto resulta igualmente en implementación de las palabras sinonímicas con intento de embellecer el discurso. Con cada nueva palabra "se pretende aportar algún nuevo matiz, ya que, en teoría no hay una sinonimia perfecta." A menudo el efecto es contraproducente - el discurso parece enfadoso (Núñez Cabezas, p. 27). La utilización de las repeticiones de este tipo sirve también para ganarse tiempo antes de responder más acertadamente.

A los ejemplos del uso de la sinonimia se incluyen los esquemas coordinados ponderativos - es la utilización de grupos de adjetivos o sustantivos que tienen un significado próximo. De estos se puede distinguir (Fernandéz Lagunilla, II, p. 77):

- coordinaciones de dos adjetivos, por ejemplo: "Este acto es un acto de paz, porque todo acto que certifique y haga cumplir la letra, la palabra [...]."; "En esta oportunidad es claro, público, notorio, conocido nacional e internacionalmente [...]."; "Como locos, descocados, enloquecidos andan los gobiernos satélites del imperialismo norteamericano, inventando, haciendo, presionando, gritando."; "[...] no haya una campaña persistente, diaria, permanente durante 20 años de manipulación y mentira sobre la Revolución Bolivariana." (Maduro 2019a).

- coordinaciones de dos o tres sustantivos, como ejemplo: "[...] pero en el mundo a veces es muy difícil soportar tantas campañas de mentira y manipulación, aunque los pueblos tienen visión, olfato, intuición." (Maduro 2019a).

\subsubsection{Alargamiento de las frases}

En muchas ocasiones los políticos buscan una manera para ganar el tiempo, por ejemplo, para elegir las palabras más adecuadas o reflexionar antes de responder. La perífrasis les ofrece esta posibilidad. Esta figura retórica sustituye formulas simples por las más complejas, que parecen rebuscadas e ingeniosas. Entre los abundantes ejemplos susceptibles de ser citados para ilustrar esta relación de sustituir encontramos el cambio de claramente por con claridad, inmediato por con carácter inmediato (Núñez Cabezas, pp. 30-31).

A continuación un fragmento del juramento presidencial de Nicolás Maduro: " $Y$ también de manera muy especial quiero extender mis brazos para saludar y darle la bienvenida a nuestros hermanos de los movimientos sociales [...]." (Maduro 2019a). En este caso "extender mis brazos para saludar y darle la bienvenida" es una forma de alargar un simple saludo. 
El otro modo que contribuye al alargamiento de la frase es la implementación de la enumeración ascendente innecesaria que significa pasar de lo particular a lo general solamente para emplear el estilo altisonante: "Venezuela tiene un pueblo que participa permanentemente en los procesos sociales, económicos y políticos de sus comunidades, de su región, del país." (Maduro 2019a). Sería suficiente con usar el último término, ya que incorpora a todos los demás.

\section{Léxico}

El léxico de los discursos populistas permite conocer las sociedades, su punto de vista y observar los cambios que ocurren en estas durante el tiempo. „El léxico político es un reflejo de la sociedad. La presencia de unos determinados términos nos proporciona datos de lo que es una sociedad, y, lo que es más importante, la ausencia de ciertas palabras es tan significativa como su aparición." (Rebollo Torío, p. 34). Algunos vocablos aparecen con más frecuencia que otros, poniendo de manifiesto los temas y problemas más actuales en estos países, pero también la ideología de sus líderes.

\subsection{Frases hechas y proverbios}

La implementación de las frases hechas o las construcciones de la lengua coloquial sirve, una vez más, para evocar las connotaciones, lo cual, a su vez está relacionado con la función de la comunicación política que es agitar (Fernández Lagunilla, II, p. 73). Como todos los componentes con valor afectivo son sujetos del proceso de desactualización que ocurre a lo largo del tiempo. Para ilustrar lo arriba mencionado, hay ejemplos de discursos de los presidentes examinados: a lo largo y ancho, de punta a punta, cara a cara, ver con buenos ojos, paraísos fiscales, con calidad y calidez, poco a poco. Y así: "Problemas hay, que levante la mano el gobierno que no tiene problemas." (Maduro 2019a); "[...] anoche en su programa, que ayer tuvo full sintonía ¿no?, Con el mazo dando. Más o menos." (Maduro 2019a). Esto lo dijo Maduro durante su juramentación y que contiene un fragmento de la frase hecha " $A$ Dios rogando y con el mazo dando" que apunta la importancia de esforzarse para cumplir los objetivos. Por otro lado una cita significativa de Morales: "Yo decía "hay que voltear la tortilla" como decimos." (Morales 2014).

También se puede encontrar con un ejemplo de una palabra coloquial que se usa solo en Venezuela para hablar de personas que se dedican al contrabando y que cruzan las fronteras ilegalmente: “ Es contigo, bachaquero! Que robas 
al pueblo, bachaquero. Es contigo, que vives junto al pueblo y lo robas todos los días." (Maduro 2019a). Y otra interesante más: " $A$ cada once le llega sus trece, decimos en Venezuela, a cada Carmonazo le llega su pueblazo." (Maduro 2019b). Esta es una paráfrasis del refrán "A cada cerdo le llega su San Martín" y significa que vendrá el momento para pagar por el daño. Nicolás Maduro se refiere al golpe de estado de 2002 dirigido por Pedro Carmona Estanga que terminó con la reposición de Hugo Chávez como presidente (Martínez, pp. 7-20). La paráfrasis funciona como metáfora, pero también como el eufemismo porque Maduro evita el significado literal. El lenguaje político no puede ser críptico, por lo tanto, Maduro usó un refrán universalmente conocido.

\subsection{La derivación: sufijos y prefijos}

\subsubsection{Sufijos}

Los sufijos aumentativos como -on, -azo (Carmenazo), -illo atribuyen el significado valorativo (negativo o positivo) mientras que los sufijos -ismo e ista son generalmente peyorativos. Hay que recordar que estamos hablando de los valores que adscriben estos sufijos a los termines que aparecen en el lenguaje político. La causa de las connotaciones negativas del sufijo -ismo origina del significado de este sufijo que corresponde a la noción de "sistema" o "doctrina" (Fernández Lagunilla, II, p. 37). El empleo de los -ismos parece poseer la habilidad de impresionar al oyente: "Los sufijos -ismo, -ista, que son los de empleo más abundante, se entienden en función de su uso apelativo para el ciudadano. Con ellos el político confiere un valor técnico-científico, un toque de autoridad a su mensaje. En ocasiones [...] lo que se intenta es vender como doctrina." (de Santiago Guervós, p. 66). De ahí resulta que cuando la intención de un político es estar entendido, usa los coloquialismos; si quiere mostrar su conocimiento de alguna área, utiliza tecnicismos.

La raíz de estas palabras nuevas derivadas viene de adjetivos, verbos, nombres, con mucha frecuencia del nombre de algún político (no necesariamente uno con la autoridad de mayor rango) como por ejemplo "el chavismo". Este último término que origina del apellido de Hugo Chávez que abarca la ideología y el estilo de gobernar que representaba este presidente de Venezuela. No se debe olvidar, sin embargo, que aunque "el chavismo" es una corriente que aún hoy provoca cierta polémica, para algunos, como el presidente actual de Venezuela - Nicolás Maduro - tiene significado valorativo positivo ya que la intención de este último es continuar la política 
de Hugo Chávez. Pero la inclusión del "chavismo" en el discurso de la oposición venezolana implica obviamente un tono negativo.

\subsubsection{Prefijos}

A los prefijos utilizados más frecuentemente se incluyen (Santiago Guervós, p. 255): anti- (antimperialismo), auto- (autoengañarse), pro- (procapitalista, proneocolonialista), contra-, ex-, macro-, mini-, pluri-(plurinacional), sobreetc. Se subraya la creación redundante de nuevas palabras usando prefijos, porque "en general, al político ignaro le gustan las palabras con prefijos; parecen más técnicas." (de Miguel Rodríguez, p. 99). En los discursos de Morales y Maduro se observa palabras con el prefijo anti- con mucha frecuencia. No es una afición por palabras técnicas, sino su declaración de la protesta, su actitud hasta lo que la palabra (la raíz derivada a través de la adición del prefijo) representa. Un ejemplo del uso del prefijo en un discurso de Morales es el siguiente: "Mi gran deseo: [...] que lindo sería, de acá a poco tiempo [si] todos los presidentes de CELAC $C^{3}$, sean antiimperialistas, anticolonialistasy anticapitalistas." (Morales 2014). Como hemos mencionado en el párrafo anterior, el sufijo -ista también intensifica esta declaración.

\subsection{La lengua ofensiva}

Casi cada técnica a la que se recurren los políticos en la comunicación política tiene un significado valorativo. Son muy raros los casos de valor neutro. Los políticos usan varias figuras retóricas para descalificar o insultar sus adversarios (eufemismos, metáforas etc.). En la política actual encontramos muchos ejemplos de la descalificación del adversario en cuanto no solo a su ideología, pero también a su personalidad. Las emociones generadas por insultar y ridiculizar o la utilización de la lengua ofensiva dinamizan la vida política.

Aquí insertamos un fragmento de la juramentación de Maduro, en el que menciona dos personas: Henry Ramos Allup (un candidato al cargo de presidente) y Todd Robinson (un diplómatico estadounidense expulsado de Venezuela por Maduro) (Maduro 2019a):

"El más famoso de todo es un diputado llamado Henry Ramos Allup, desde aquí le envió un saludo a Henry Ramos Allup - quien creía tener un liderazgo para ganar las elecciones presidenciales. Me hubiera gustado competir y derrotarte, Ramos Allup, en las elecciones del 20 de mayo,

\footnotetext{
${ }^{3}$ CELAC - Comunidad de Estados Latinoamericanos y Caribeños.
} 
pero sabemos que la embajada gringa, el encargado de negocios de apellido Robinson, que ya no está en Venezuela, lo llamó, lo amenazó, le amenazó la familia y de un día para otro cambió el discurso y se rajó y se escribió su candidatura presidencial, a pesar de que había hecho todos los preparativos para ser candidato presidencial."

En este fragmento corto Maduro utiliza la lengua ofensiva ridiculizando la candidatura de Ramos Allup. Además, menciona a Todd Robinson describiéndolo como "de apellido Robinson" (para enfatizar aún mayor distancia entre ellos) y la embajada estadounidense con el adjetivo "gringa" que en varios países hispanoamericanos sirve para describir al extranjero que no habla español de manera despectiva.

En otra ocasión Evo Morales cita insultos de sus opositores que lo compararon con Osama bin Laden y con eso evocar el contexto de terrorista: “...] esa vez acusado de narcotraficante, de bin Laden andino." (Morales 2014).

La inclusión de la lengua ofensiva en el discurso parece como un control ineficaz de las emociones. Sin embargo, se observa que hablar sin rodeos de manera ofensiva es una exhibición de poder y es requerido que los oficiales la utilicen en el lenguaje oficial. La selección de palabras rudas o insultos significa la ruptura con el tabú - el político parece supremo porque no le afectan las normas vigentes sobre la comunicación oficial (Wasilewski, pp. 328-329). Para ilustrar lo arriba mencionado, se puede utilizar un fragmento del enunciado de Maduro después de que Donald Trump lo haya nombrado narcotraficante:

"El gobierno de Donald Trump, en una acción extravagantemente extremista, vulgar, miserable, lanzó un conjunto de acusaciones espurias, falsas. [...] Así se lo digo: 'jEres un miserable Donald Trump!'. Él actúa no solo como un cowboy, racista y supremacista, él maneja las relaciones internacionales como un extorsionador." ${ }^{4}$

Como se puede observar, las palabras dirigidas al presidente Trump son muy directas e irrespetuosas, pero el presidente Trump utiliza la misma técnica.

4 Agencia AFP. "Eres un miserable", dice Maduro a Trump tras ser acusado por EE.UU. de narcoterrorismo. "El comercio". 26.03.2020.

https:/www.elcomercio.com/actualidad/miserable-maduro-trump-narcoterrorismo-venezuela.html [acceso: 23.06.2020] 


\section{Conclusiones}

Una de las características del lenguaje político es la implementación de las ambigüedades que sirven para conseguir votos. El análisis de los discursos de Evo Morales y de Nicolás Maduro permite concluir que las características de su populismo son evidentes, tanto en contenido de los discursos, como en el lenguaje. El pueblo está en el centro de la misión de estos dos políticos cuyo rol es actuar en nombre de los ciudadanos - ser un líder. El pueblo siempre está en contra a las élites. Finalmente siempre hay un adversario que amenaza la libertad del pueblo. En ambos casos resulta que el mayor adversario de los dos países latinoamericanos son EE.UU.

El lenguaje que utilizan ambos está simplificado y en gran parte adaptado al receptor común con finalidad de ser lo más accesible. Por lo tanto, los enunciados provocan la evaluación de la situación actual a través de metáforas y conllevan una carga emocionante. La manera en la que se comunican los dos presidentes forma un conjunto coherente con los papeles que tienen, es decir el asociado, casi miembro de la familia o el defensor, sin olvidar de sus cargos oficiales asignados.

Los ejemplos citados en este trabajo demuestran que en general los discursos de Nicolás Maduro y Evo Morales son bien recibidos y, en situaciones cuando no hay motivos por exteriorizar los sentimientos, no son accidentales. La aparición de la lengua ofensiva es, más bien, la exhibición del poder. Los rasgos populistas de estos discursos demostrados en este trabajo facilitan entender la popularidad que ganaron ambos presidentes cuando se encontraban en sus cúspides.

\section{BIBLIOGRAFÍA}

Fuentes directas:

Constitución de la República Bolivariana de Venezuela (1999).

Constitución Política del Estado Plurinacional de Bolivia (2009).

Maduro, N. (2019a). Discurso de juramentación como presidente constitucional de la República Bolivariana de Venezuela para el periodo de 2019-2025, 10.01.2019, Ministerio del Poder Popular para Relaciones Exteriores; http://mppre.gob.ve/discurso/juramentacion-tsj-nicolas-maduro-presidente/

Maduro, N. (2019b). Discurso después de la autoproclamación de Juan Guaidó como presidente interino, 23.01.2019. (transcripción propia);

https://www.youtube.com/watch?v=xKdgiKYAUdA 
Maduro, N. (2020). Discurso en el que reclama huecos en calles de 23 de Enero y Catia, y exige que plan de asfaltado funcione, 30.01.2020. (transcripción propia); https://www.youtube.com/watch?v=vcFwPEvWAdI

Morales, E. (2014). Discurso después del otorgamiento del título de Doctor Honoris Causa en la Universidad Nacional de Entre Ríos, Argentina. 13.12.2014. (transcripción propia); https://www.youtube.com/watch?v=ECxz37kRjSQ

Morales, E. (2019a). Discurso en la 74a Asamblea General de la Organización de las Naciones Unidas, EE.UU., 24.09.2019. (transcripción propia); https://www.youtube.com/watch?v=AZb-dOWCc_w

Morales, E. (2019b). Discurso tras renunciar a la Presidencia de Bolivia, 10.11.2019. (transcripción propia); https://www.youtube.com/watch?v=mUPkAv5E5ks

Fuentes indirectas:

Albertazzi, D. \& McDonell, D. (2008). Twenty-First Century Populism. Hampshire, New York: Palgrave Macmillan.

Barańczak, S. (1983). Czytelnik ubezwłasnowolniony: perswazja w masowej kulturze PRL. Paryż: Libella.

Dankowski, M. Z. \& Orłowska, N. (2016). Ameryka Eacińska. Dzieje i kultura. Gdańsk: Wydawnictwo Uniwersytetu Gdańskiego.

de Miguel Rodríguez, A. (1994). La perversión de lenguaje. Madrid: Espasa-Calpe.

de Santiago Guervós, J. (2018). Léxico político de la transición: La lengua de la Constitución de 1978. Salamanca: Universidad de Salamanca.

Diezhandino Nieto, M.P. (1994). El quehacer informativo. Bilbao: Universidad del País Vasco.

Fernández Lagunilla, M. (2014). La lengua en la comunicación política I: El discurso del poder. Madrid: Arco Libros S.L.

Fernández Lagunilla, M. (2014). La lengua en la comunicación política II: La palabra del poder. Madrid: Arco Libros S.L.

Guardiola Rivera, Ó. (2010). Como construir sociedades: Diez cosas que nunca nos dicen sobre la paz y la guerra. Bogotá: Editorial Pontificia Universidad Javieriana.

Hernando, B. M. (1990). Lenguaje de la prensa, Madrid: Eudema.

Lakoff, G. (2007). No pienses en un elefante. Lenguaje y debate político. Madrid: Editorial Complutense.

López Maya, M. (2016). La crisis del chavismo en la Venezuela actual, Estudios Latinoamericanos. Nueva Época, núm. 38.

Martínez, J. H. (2012). El golpe de abril: El Estado Nacional Venezolano ante la globalización neoliberal, Historia Actual Online, núm. 28.

Núñez Cabezas, E.A (2000). Aproximación al léxico del lenguaje político español. Málaga: Universidad de Málaga.

Ortega Carmona, A. (1999). El discurso político, Madrid: Fundación Cánovas del Castillo.

Rebollo Torío, M.A. (2002). Caracterización del lenguaje político, [en:] Testi specialistici e nuovi saperinelle lingue iberiche, coord. D.A. Cusato, L. Fratalle, Messina: Andrea Lippolis Editore.

Sivak, M. (2010). The extraordinary Rise of the First Indigenous President of Bolivia. New York: Palgrave Macmillan.

Wasilewski, J. (2009). Łamanie tabu jako komunikat dominacyjny. Tabu w języku i kulturze, „Język a Kultura”, t. 21, Wrocław: Wydawnictwo Uniwersytetu Wrocławskiego. 